\title{
PATRIA, ESTADO Y LEGITIMIDAD RELIGIOSA EN LA TEORÍA POLÍTICA DE CICERÓN
}

\author{
Juan José Ferrer Maestro \\ Universitat Jaume I
}

RESUMEN: Este trabajo analiza los conceptos de patria, nación y estado en los escritos de Cicerón, su influencia posterior, y la importancia de la religión y el ejercicio de los cargos sacerdotales en las decisiones institucionales. Entre algunos politólogos, la república romana $-\mathrm{y}$ en general las comunidades políticas de la antigüedad- no debe ser considerada un estado porque carece de las características que ellos solo reconocen a partir de la edad moderna, pero las palabras de Cicerón y la propia organización constitucional de la res publica romana confirman que los ciudadanos romanos se organizaron en una comunidad que presenta los mismos rasgos que aquellas otras que, desde Maquiavelo, llamamos estados.

Palabras clave: Conceptos políticos en Cicerón, patria, estado, nación.

ABSTRACT: This paper analyses the concepts of homeland, nation and state in the writings of Cicero, their subsequent influence, and the importance of religion and the exercise of priestly offices in the making of institutional decisions. Among some political scientists, the Roman republic, and in general political communities of antiquity, should not be considered a state because it lacks the distinctive features that the only recognise from the modern age onwards. But the words of Cicero and the constitutional organization of the Roman res publica, confirm that the Roman citizens organised themselves in a community with the same features as those which, since Machiavelli, we call states.

Keywords: Cicero's political terms, homeland, state, nation. 


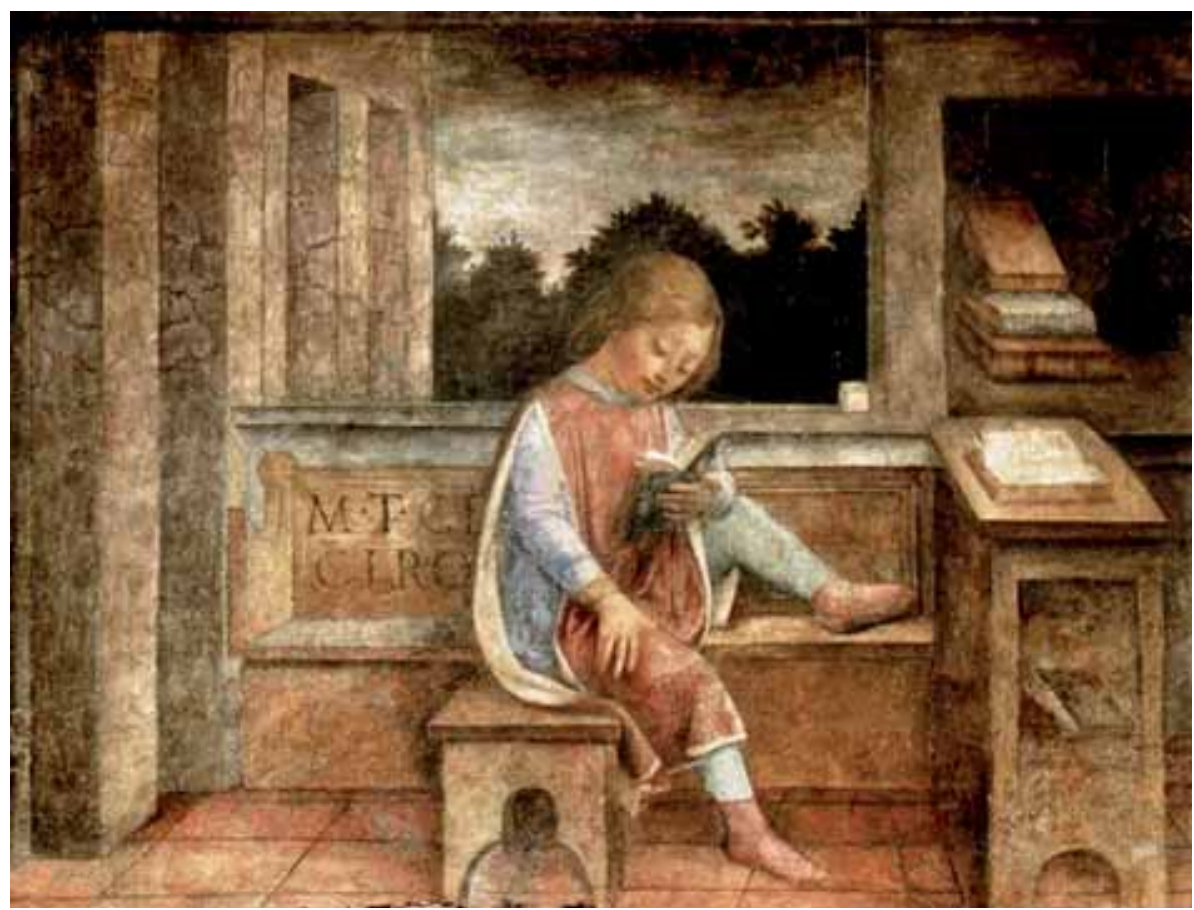

El joven Cicerón leyendo, Vincenzo Foppa, fresco, 1464 (Wallace Collection)

En una comunidad administrativamente tan compleja como la que resultó Edel amplio proceso expansivo de la república, los romanos siguieron fieles a su modelo de estado a pesar del grave desasosiego social provocado por los enormes beneficios derivados de las conquistas territoriales y su injusto reparto. El enfrentamiento interno en pos de territorios, botines y exacciones generó una lucha de poder entre los miembros de la nobleza y su fraccionamiento en las tendencias políticas de optimates y populares, pero en ningún caso se llegaron a socavar los privilegios de la aristocracia ni, por supuesto, la auctoritas del senado y su proyección como máxima institución del estado. Pero, ¿qué estado?, ¿cómo definían los romanos a su propia comunidad en el siglo i a. C.? La respuesta podemos hallarla en las palabras que Cicerón puso en boca de Escipión:

La República es la cosa propia del pueblo, pero pueblo no es toda reunión de hombres, congregados de cualquier manera, sino un conjunto asociado de hombres que aceptan las mismas leyes y tienen intereses comunes (Cic., de re publica, 1, 39). ${ }^{1}$

1. Res publica res populi, populus autem non omnis hominum coetus quoquo modo congregatus, sed coetus multitudinis iuris consensu et utilitatis communione sociatus. 
Hermann Heller, en su Teoría del Estado, cuestionó el pensamiento contemporáneo que relaciona pueblo y estado: «la unidad estatal no puede identificarse con ninguno de sus elementos. El Estado (...) no está formado por hombres, sino por actividades humanas» (Heller, 1942: 255). Se percibe en esta afirmación una coincidencia con los argumentos de Cicerón antes expuestos, a pesar de la resistencia del jurista y politólogo alemán en aceptar la existencia del Estado con anterioridad a la edad moderna (Heller: 1942: 141 ss.). Pero me cuesta aceptar esta conclusión de Heller, pues si acertara en su análisis y no pudiéramos hablar de Estado en Roma ¿qué cosa fue entonces la República romana? Y sobre todo qué cosa fue distinta a esa afirmación de Heller de que «el Estado (...) no está formado por hombres, sino por actividades humanas», o es que ¿acaso la República no fue un conjunto de instituciones con capacidad para tomar decisiones que afectaban a cientos de miles de personas, y cuyas interrelaciones debemos calificar de actividades humanas?

Cuando Heller define el Estado dice de él que «el poder de la organización estatal se diferencia de cualquier otro únicamente por la clase de coacción que aplica, así como por la específica relación de la dominación con el territorio. Las decisiones adoptadas por los órganos estatales 'capacitados' poseen obligatoriedad general no solo para los que sean jurídicamente miembros de la organización estatal, sino, en lo fundamental, para todos los habitantes del territorio. En virtud de esta propiedad, el Estado se considera como un grupo territorial de dominación, a diferencia de los grupos de carácter personal. El Estado se diferencia de todos los otros grupos territoriales de dominación por su carácter de unidad soberana de acción y decisión» (Heller, 1942: 255). En esta cita se puede vislumbrar el antagonismo entre los «grupos de carácter personal» y «el grupo territorial de dominación» aplicado a las circunstancias personales de nuestro politólogo. ${ }^{2}$ E incluso se puede aceptar, para el caso romano, que la oligarquía senatorial o el ordo publicanorum representaban «grupos de carácter personal» dentro o al margen de las instituciones republicanas. Pero en ninguno de los dos casos desaparecía el Estado, porque si así fuese desaparecería en todos y cada uno de los momentos históricos en los que los «grupos de carácter personal» impusieron sus decisiones e intereses al conjunto de «todos los habitantes del territorio», embozados espuriamente como si se tratase del «grupo territorial de dominación» que se apropia de la «unidad soberana de acción y decisión». Y a lo largo de la historia tal circunstancia ha sido recurrente.

En mi propia percepción el Estado es una comunidad humana dotada de unas normas de convivencia, jerarquizada y con un territorio que le es propio. Dichas normas pueden estar escritas o no, y al mismo tiempo ser impuestas o elegidas libremente. En cuanto al territorio, puede hallarse delimitado o simplemente constituido en un entorno dotado de medios de

2. Hermann Heller se exilió de Alemania en 1933, con la llegada del nazismo al poder, y falleció en Madrid en el mismo año. 
subsistencia sobre los cuales se ejerce la soberanía. Esta definición, que utilizo pedagógicamente, me permite hacer más comprensible el paso trascendental de las comunidades aldeanas a las organizaciones estatales que se dio en la antigüedad, para familiarizarse con el esquema institucional de las complejas sociedades que los jóvenes estudiantes van a conocer a partir de entonces. Y el caso concreto de la República romana no es ajeno a estas formulaciones.

Desde el punto de vista constitucional y funcional, Roma es el conjunto de instituciones que conforman el Pueblo y el Senado, pero lo realmente distintivo, es decir, los rasgos que distinguen al individuo romano de quien no lo es, son la condición masculina y el derecho de ciudadanía. Todos tenemos patria, porque cada uno de nosotros pertenece a algún lugar ancestral, pero la patria de los romanos es la patria común de los ciudadanos, unidos por esa circunstancia legal y excluyente que apenas nos sorprende porque sigue formando parte como elemento fundamental del derecho que los romanos legaron a nuestra cultura occidental.

Cicerón supo describir de manera comprensible ese aspecto imprescindible de la relación entre el ciudadano y la patria, distinguiendo entre el terruño familiar y la condición política, como puede apreciarse en el siguiente fragmento de Sobre las leyes, la obra en la que expuso el concepto estoico de unas normas basadas en la razón y sancionadas por los dioses, y en la que discute disposiciones legales conectadas con la religión y las magistraturas políticas. Una obra que el autor dedicó a la formulación de los principios por los que debía regirse el estado perfecto que previamente había diseñado en su obra Sobre la República. Este es el diálogo entre Cicerón y su fraternal T. Pomponio Ático:

Ático: ¿qué significa lo que has dicho hace un momento acerca de que este lugar -al que creo que llamas Arpino- es tu verdadera patria? ¿Es qué tenéis dos patrias? ¿No tenemos una patria común a todos? Tal vez creas que la patria del sabio Catón fue Túsculo y no Roma.

Marco (T. Cicerón): Sí, ciertamente, Catón al igual que todos los hombres de los municipios tienen dos patrias, una por nacimiento y otra por ciudadanía; como Catón nació en Túsculo y recibió la ciudadanía de Roma era tusculano por su origen y romano por ciudadanía, tuvo una patria geográfica y otra de derecho; (...) así nosotros llamamos patria aquella en la que hemos nacido y aquella que nos ha recibido. Pero es necesario amar sobre todo a la que nos une a todos los ciudadanos bajo el nombre de República, por la cual debemos morir y a la que debemos dedicarnos por completo, entregándole y consagrándole lo que nos pertenece (Cic., de legibus, 2, 5). ${ }^{3}$

3. Atticus: ... Sed illud tamen quale est quod paulo ante dixisti, hunc locum -id enim ego te accipio dicere Arpinum -germanam patriam esse vestram? Numquid duas habetis patrias, an est una illa patria communis? Nisi forte sapienti illi Catoni fuit patria non Roma sed Tusculum.

Marcus: Ego mehercule et illi et omnibus municipibus duas esse censeo patrias, unam naturae, alteram civitatis: ut ille Cato, quom esset Tusculi natus, in populi Romani civitatem susceptus est, itaque quom ortu Tusculanus esset, civitate Romanus, habuit alteram loci patriam, alteram iuris; (...) sic nos et eam patriam 
La patria común, por tanto, es Roma, identificada como res publica, en tanto designa el conjunto de instituciones públicas compuestas por el cuerpo de ciudadanos; el estado en suma, al margen del sentimiento geográfico de origen del que todos proceden. Pero la patria común que Cicerón postula es también añadido de agradecimiento y amor, y tan exigente que al servirla hay que llegar si es menester hasta la muerte:

[...] no hay relación más venerada ni más digna de nuestro amor que la que cada uno de nosotros tiene con la República. Amamos a nuestros padres, a nuestros hijos, a los parientes, a los amigos, pero solo la patria comprende a todos y cada uno de los que nos son queridos; por ella ¿qué hombre de bien dudará en lanzarse a la muerte para servirla? (Cic., de officiis, 1,57$){ }^{4}$

Y esta sinonimia de patria y república, de patria y estado, la encontramos de nuevo en este párrafo del Sueño de Escipión:

Pero, oh Africano, para que puedas ser el más entregado al bienestar de la república, escucha bien: para todos los que han guardado, animado y ayudado a su patria, hay asignado un lugar particular en el cielo, en donde los bendecidos gozarán de vida permanente. Pues nada sobre la tierra es más aceptable a la deidad suprema que reina sobre todo el universo, que las uniones y combinaciones de hombres unidos bajo la ley a las que llamamos estados; por tanto los gobernantes y conservadores proceden de ese lugar y a él retornan después (Cic., de re publica, 6,13$).^{5}$

En los tiempos presentes, el concepto de nación se utiliza con preferencia como sinónimo de Estado o de sus ciudadanos. Es su acepción política, pero también está ligada al sentimiento de origen que antes he citado y se identifica mediante un marcado carácter cultural. En este sentido define un grupo humano vinculado por la solidaridad y la lealtad al grupo mismo, por encima de cualquier otra lealtad contrapuesta. Según Rustow (1974: 301) esta definición fue propuesta en primer lugar por John Stuart Mill (Considerations on Representative Government, 1861, cap. 6), pero los historiadores de la

dicimus ubi nati, et illam $<a>$ qua excepti sumus. Sed necesse est caritate eam praestare $<$ e $>$ qua rei publicae nomen universae civitati est, pro qua mori et cui nos totos dedere et in qua nostra omnia ponere et quasi consecrare debemus. He utilizado convenientemente las traducciones de J. Guillén y A. D'Ors sobre las obras De officiis, De re publica y De legibus, en las ediciones españolas de Alianza ed., Tecnos y Biblioteca Clásica Gredos, y de M. Balasch sobre las Historias de Polibio, en Gredos. Además, las ediciones inglesas en Loeb C. L. de E. W. Sutton en el De oratore, y W. R. Paton para las Historias de Polibio.

4. Omnium societatum nulla est gravior, nulla carior quam ea, quae cum re publica est uni cuique nostrum. Cari sunt parentes, cari liberi, propinqui, familiares, sed omnes omnium caritates patria una complexa est, pro qua quis bonus dubitet mortem oppetere, si ei sit profuturus?

5. Sed quo sis, Africane, alacrior ad tutandam rem publicam, sic habeto, omnibus, qui patriam conservaverint, adiuverint, auxerint, certum esse in caelo definitum locum, ubi beati aevo sempiterno fruantur; nihil est enim illi principi deo, qui omnem mundum regit, quod quidem in terris fiat, acceptius quam concilia coetusque hominum iure sociati, quae 'civitates' appellantur; harum rectores et conservatores hinc profecti huc revertuntur. 
antigüedad sabemos que los griegos ya utilizaron señas de identidad cultural como muestra de lealtad al grupo, mostrando su rechazo a toda elemento «bárbaro», es decir, no griego; al igual que los romanos, posteriormente, adoptaron esta expresión helena para aplicarla a su vez a todos aquellos que consideraban ajenos a la cultura latina.

Para G. Leibholz (1964: 205-206) «los pueblos, en oposición a las naciones, han existido tanto en la Antigüedad como en la Edad Media y en la llamada Edad Moderna». Pero esta afirmación puede prestarse a confusión por la identificación que puede hacerse, tanto con el cuerpo jurídico de un estado como con el segmento de ciudadanos menos favorecidos (DE Blas GuERrERo, 1984: 35 ss.). En cambio, Cicerón llama nationes a ese mismo concepto de pueblo que utiliza Leibholz:

Todas las naciones pueden ser sometidas a esclavitud, pero nuestra comunidad no puede (Cic., Philippicae, 10, 20). ${ }^{6}$

«Nuestra comunidad», ese parece el mejor tratamiento político para traducir aquí nostra civitas, pues es el modo más comprensible de oponer natio y civitas en este párrafo. Cicerón, queda demostrado, ensalza los conceptos de patria y estado, de civitas como comunidad de ciudadanos opuesta a las naciones, es decir a los pueblos que carecen del orden constitucional que el arpinate admira en su idealizada república romana.

En el libro segundo de Sobre las leyes, podemos leer un elaborado alegato a favor de la distinción entre derecho civil y derecho religioso o pontificio:

Muchas veces -dice el hijo de Publio $-^{7}$ oí decir a mi padre que nadie podía ser buen pontífice si no conocía el derecho civil» ¿Todo entero? ¿Y por qué? ¿Qué tiene que ver con el pontífice el derecho relativo a las paredes, a las aguas, o a ninguna otra cosa, excepto lo que va unido a la religión? (Cic., de legibus, 2,47$).{ }^{8}$

No sorprende esta postura de Cicerón, pues como experto jurista y defensor civil no acepta de buen grado la intromisión de este colegio sacerdotal. Su exigencia en la delimitación de los ámbitos jurídicos es el resultado de su reflexión práctica y competencial; no es una respuesta dictada por la razón, pues de haberlo sido, la postura ciceroniana habría llegado al

6. Omnes nationes servitutem ferre possunt, nostra civitas non potest.

7. Se refiere a P. Mucio Escévola, cónsul en 133 a. C. y gran maestro del derecho.

8. 'Saepe' inquit Publi filius 'ex patre audivi, pontificem bonum neminem esse, nisi qui ius civile cognosset. Totumne? Quid ita? Quid enim ad pontificem de iure parietum aut aquarum aut luminum nisi eo quod cum religione coniunctum est? 
extremo de exigir la secularización de todo el derecho, y sin embargo, su acatamiento al orden moral tradicional (del que la religión es parte indisoluble) es evidente. Sirve como ejemplo este expresivo fragmento:

Conservar los ritos de la familia y de los padres es como conservar una religión transmitida por los dioses, porque la antigüedad se aproxima mucho a los dioses (Cic., de legibus, 2, 27). ${ }^{9}$

Más allá de una simple primera lectura, estas palabras muestran el sesgo legítimo que la religión otorga a los gestos sociales, pero sin necesitar (ni desear) la existencia de un corpus doctrinal escrito, pues la tradición, basada en ritos familiares, es superior a toda verdad revelada. La semejanza con los dioses viene dada por el carácter atávico de esas tradiciones, y la importancia simbólica que Cicerón le otorga es innegable.

$\mathrm{Su}$ referencia a la tradición incluye el buen orden y el cumplimiento de unas normas que parte de un corpus jurídico constitucional, en el que Cicerón sitúa el equilibrio de sus aspectos religiosos y políticos, porque la religión es inseparable del poder y por ella queda legitimado:

[...] sin el concurso de los sacerdotes públicos no se pueden cumplir las ceremonias religiosas privadas, porque es manifiesto que la República necesita del consejo y el pueblo de la autoridad de los optimates (Cic., de legibus, 2, 30). ${ }^{10}$

Y si la tradición reconocida por las leyes encuentra su nexo de unión con el derecho a ejercer la autoridad, mediando prácticas religiosas reservadas a unos pocos privilegiados, el círculo de la legitimidad atávica queda oportunamente cerrado:

Pero el derecho mayor y el de más trascendencia en la República es el derecho augural, que va unido a la autoridad. Y no pienso de esta forma porque yo soy augur, sino porque así debemos de creerlo (Cic., de legibus, 2,31 ). ${ }^{11}$

Si un jurista de tanto prestigio, un argumentador y teórico inigualable en el ámbito del pensamiento político, asegura que «así debemos de creerlo», se entiende que en la escala de valores constitucionales existen preceptos morales incuestionables sobre los que no cabe mayor explicación. No parece tratarse de dogmatismo impuesto, sino más bien una «condicio» de la propia esencia de ser romano. Pero hay algo más. Cicerón no puede sustraerse al efecto de la

9. Iam ritus familia patrumque servare, id est, quoniam antiquitas proxume accedit ad deos, a dis quasi traditam religionem tueri.

10. ut sine iis, qui sacris publice praesint, religioni privatae satis facere non possint. Continet enim rem publicam, consilio et auctoritate optimatium semper populum indigere.

11. Maximum autem et praestantissimum in re publica ius est augurum cum auctoritate coniuctum, neque vero hoc quia sum ipse augur ita sentio, sed quia sic existimari nos est necesse. 
vanidad, que en él asoma con la facilidad que demuestran sus lamentos por la ingratitud y el desprecio que le mostraron «los enemigos de la República», la misma que le otorgó el título de «conservador de la patria» (de legibus, 2, 42). Una vanidad que acompaña la admiración con que describe las amplias competencias del poder augural:

¿Qué prerrogativa mayor, si hablamos de derecho, que disolver los comicios o las asambleas convocadas por los magistrados dotados de imperio, o por los más altos poderes políticos, o anularlas una vez que se han celebrado? ¿Qué poder más sorprendente que suspender una acción emprendida, si un solo augur dice 'para otro día'? ¿Qué hay más grande que poder decidir que los cónsules renuncien a su magistratura? ¿Qué hay más delicado que conceder o rehusar el derecho de convocar al pueblo o a la plebe? ¿Y qué diremos del derecho de abolir las leyes votadas ilegalmente (...)? De cuanto se realiza en el interior o por medio de las armas nada puede ser aprobado por nadie, sin la autorización de los augures (Cic., de legibus, 2, 31). ${ }^{12}$

Incluso, ante las dudas expuestas por su amigo Ático sobre si la capacidad de adivinar es real o inventada para utilidad de la República, Cicerón comienza su respuesta preguntándose previamente y con asombro cómo podría negar él la adivinación: non video cur esse divinationem negem (de legibus, 2, 32), y la finaliza con una afirmación ambigua y débil, de muy escasa consistencia para su sobrado talento: «entre nuestros mayores creo que tuvo ese doble carácter, en parte sirvió a las circunstancias de la República y en parte sirvió muchas veces para tomar decisiones» (Cic., de legibus, 2, 33). ${ }^{13}$

El viejo Catón - por quien Cicerón muestra una viva admiración y respeto (de re publica, 2, 1)-, el mismo que aconseja en su tratado Sobre agricultura un comportamiento piadoso y profiláctico, ${ }^{14}$ declaraba que dos augures no podían mirarse a la cara sin echarse a reír (Cic., de re publica, 2, 51). Todo ello es prueba de un cierto utilitarismo religioso, el mismo que mostró Polibio al glosar la actuación militar de Escipión, cuando afirmó que la mayor parte de los hombres son incapaces de afrontar dificultades si no creen contar con protección divina para ello:

No debemos pensar que este [Licurgo] fuera tan religioso que, al redactar la constitución espartana, atendiera solo a la Pitia, así como tampoco debemos

12. Quid enim maius est, si de iure quaerimus, quam posse a summis imperiis et summis potestatibus commitiatus et concilia vel instituta dimittere vel habita rescindere? Quid gravius quam rem susceptam dirimi, si unus augur 'alio <die>' dixerit? Quid magnificentius quam posse decernere, ut magistratu se abdicent consules? Quid religiosius quam cum populo, cum plebe agendi ius aut dare aut non dare? Quid, legem si non iure rogata est tollere (...)? Nihil domi, nihil militiae per magistratus gestum sine eorum auctoritate posse cuiquam probari?

13. Quae mihi videtur apud maiores fuisse duplex, ut ad rei publicae tempus non numquam, ad agendi consilium saepissime pertineret.

14. De agri., 131, 1: piro florente dapem pro bubus facito; 132, 1: dapem hoc modo fieri oportet: Ioui dapali culignam uini quantam uis polluceto...; 160, 1: luxum si quod est, hac cantione sanum fiet; etc. 
imaginarnos que si Publio Cornelio Escipión proporcionó a su patria un imperio tan enorme, lo hiciera movido por sueños y agüeros. Ambos personajes se dieron cuenta de que la mayoría de los hombres no admite fácilmente hechos paradójicos y si no es con una confianza fundada en los dioses, no se atreven a acometer empresas difíciles (Polibio, 10, 2, 9-10). ${ }^{15}$

Añadiendo a continuación que el valor y la tranquilidad de ánimo al combatiente, se la otorga su calidad de creyente confiado:

Publio divulgó siempre entre el pueblo, que realizaba sus proyectos por inspiración divina, y así infundía confianza y ánimo en sus subordinados ante las empresas difíciles (Polibio, 10, 2, 12). ${ }^{16}$

La inspiración divina y el poder augural ejercieron una especial influencia sobre la autoridad constitucionalmente reconocida. Cicerón suele mostrar en privado su elevada autoestima como estadista y su escasa confianza en la concordia política que tanto defendía en sus opiniones escritas. ${ }^{17} \mathrm{Al}$ menos eso se desprende de su exaltación de las prerrogativas augurales:

Se concede luego a todos los magistrados los auspicios y poder judicial, de forma que permanezca el poder del pueblo, al que pueda apelarse; los auspicios para que algunos retrasos convenientes impidieran muchos comicios inútiles, pues muchas veces los dioses inmortales contuvieron el injusto ímpetu del pueblo por medio de los auspicios (Cic., de legibus, 3, 27). ${ }^{18}$

Su apelación a la concordia, para que la debida armonía mantenga una «constitución moderada», la reclama Cicerón «por medio del equilibrio del derecho, residiendo la potestad en el pueblo y la autoridad en el Senado» (Cic., Sobre las leyes, 3, 28). ${ }^{19}$ Pero este equilibrio tan bien diseñado en su teoría política no debió convencerle y por ello acudía al legítimo arbitraje del poder augural, sustentado en principios de indiscutible autoridad y prestigio de los hombres que lo ostentaron. Así lo reconocía al afirmar que «[en nuestra comunidad] primero fueron augures los reyes; después, algunos ciudadanos

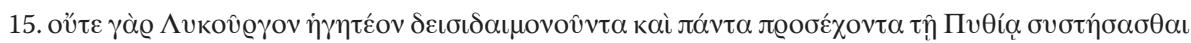

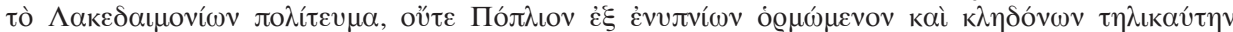

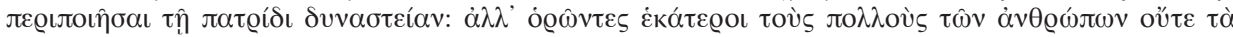

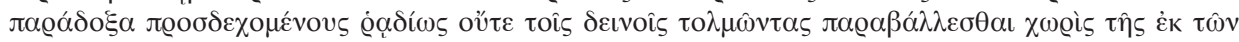
$\theta \varepsilon \hat{\jmath} v \dot{\varepsilon} \lambda \pi i ́ \delta o \varsigma$.

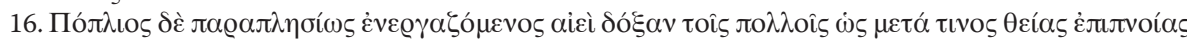

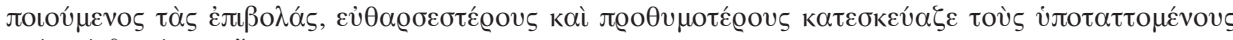

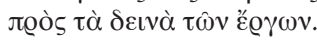

17. Al respecto de la concordia ordinum, véase Strasburger, 1956; MARCo-Pina, 2000: 290 ss.

18. Deinceps igitur omnibus magistratibus auspicia et iudicia dantur; iudicia <ita> ut esset populi potestas ad quam provocaretur, auspicia ut multos inutiles comitiatus probabiles inpedirent morae, saepe enim populi impetum auspiciis di immortales represserunt.

19. Potestas in populo, auctoritas in senatu. 
particulares revestidos de este mismo cargo sacerdotal gobernaron la república con la autoridad que provenía de la religión» (Cic., de divinatione, 1, 40). ${ }^{20}$

Dada la reconocida aversión de los romanos hacia la monarquía, esta referencia de legitimidad, sustentada en los reyes como iniciadores del proceso es curiosa pero no única en el pensamiento ciceroniano. Al menos me consta otra afirmación similar hecha al comienzo de su trabajo acerca de la formación del orador (¿qué hay tan propio de reyes?), en plena exaltación de la elocuencia:

¿Qué hay tan propio de reyes, tan noble, tan generoso, como dar ayuda al que la pide, alentar a los afligidos, restaurar la seguridad, liberar del peligro, mantener a los hombres sus derechos civiles?» (de oratore, 1,32$).{ }^{21}$

Recordemos que la religión romana es exclusivamente la religión de los romanos, como confirmó el mismo Cicerón: «cada comunidad tiene su religión, nosotros tenemos la nuestra» (pro Flacco, 28, 69), ${ }^{22}$ y cuya descripción comunitaria y carácter de culto familiar ha precisado J. Scheid, quien nos recuerda el escándalo de las Bacanales (186 a. C.) y la fuerte reacción generada en su contra. El episodio fue sentido en Roma como un crimen de estado, acompañado de un peligro latente de secesión social, dado el nivel aristocrático de alguno de sus participantes y el riesgo evidente de que pudiese generarse una comunidad distinta a la romana:

[...] era una multitud inmensa, casi otro pueblo [al margen del romano]; entre la cual se encontraban hombres y mujeres, miembros de las familias nobles [de Roma] (Livio, 39, 13, 14). ${ }^{23}$

Scheid dice que esta intolerancia, aplicada a una manifestación social que escapa a cualquier control público, es la misma que inspirará más tarde la persecución contra los cristianos (SCHEID, 1991:1-7).

Con lo expuesto hasta aquí, parece que fue más importante la finalidad no espiritual que lo formal en las prácticas religiosas. No se trataba tanto de regular las creencias, sino de controlarlas desde las instituciones públicas, con el fin de que no cuestionaran ninguno de los principios morales que aglutinaban el sentimiento de pertenencia a la patria común. En consecuencia, toda innovación sería tenida como una intromisión si propugnaba la apertura de modificaciones en la atávica solidez del estado, es decir, si cuestionaba el mos maiorum, el conjunto de tradiciones ancestrales que muy oportunamente se aprovecha para proteger los intereses de las familias dirigentes del estado romano.

20. ...In qua [nostra civitas] et reges augures et postea privati eodem sacerdotio praediti rem publicam religionum auctoritate rexerunt.

21. Quid tam porro regium, tam liberale, tam munificum, quam opem ferre supplicibus, excitare adflictos, dare salutem, liberare periculis, retinere homines in civitate?

22. Sua cuique civitate religio (...) est, nostra nobis.

23. Multitudinem ingentem, alterum iam prope populum esse; in his nobiles quosdam uiros feminasque. 
Fue en el seno del sector más conservador de estas familias donde surgió la preocupación por la situación social en la que se encontraba Roma en la época posterior al triunfo en Pidna (168 a. C.), como puede comprobarse en las palabras de Polibio al inicio de su amistosa relación con Escipión Emiliano:

La primera decisión tomada con empeño por Escipión para llevar una vida virtuosa fue conseguir una excelente reputación y el respeto de todos los hombres de su misma edad. Este objetivo era un gran premio pese a las dificultades, pero digno de perseguir en Roma en ese tiempo debido a las tendencias viciosas que existían por parte de los más jóvenes, ya que algunos de ellos se habían abandonado a la pederastia, otros frecuentaban los prostíbulos, y muchos a espectáculos o entretenimientos musicales y banquetes, y a la extravagancia que ello envolvía, infectándose rápidamente por la laxitud griega en estos vicios durante el tiempo de la guerra contra Perseo. Tan grande era la incontinencia de los jóvenes, que muchos se gastaban un talento en la compra de un jovencito ${ }^{24}$ y otros malgastaban trescientos dracmas en la adquisición de una jarra de caviar. Esto suscitaba la indignación de Catón, quien una vez dijo en un discurso público que la prueba más segura de la degradación de la República podía verse cada vez que los jóvenes ricos compraban algo que no fueran tierras y cada vez que preferían las jarras de caviar a conducir los arados (Polibio, 31, 25, 2-5). ${ }^{25}$

Esta catoniana preocupación por el patrimonio y las labores agrícolas formaban parte del más atávico sentimiento de identidad romana, especialmente tras la victoria frente a los macedonios en Pidna. El indiscutible poder universal romano y las consecuencias de su expansión iban a notarse de modo inmediato: las riquezas llegadas a Roma alteraron sustancialmente el modo de vida de sus habitantes y afectaron las tradiciones sobre las que se sustentaba un estilo aparentemente inalterado de ejercer el poder. Un estilo apoyado en el mos maiorum, que peligraba con las modas importadas y el consecuente desorden de las costumbres tradicionales romanas. Por tanto,nodebe extrañar la preocupación por todo lo que llegaba de Grecia y la respuesta en el seno de la sociedad dirigente romana, cuyo estandarte conservador enarboló vigorosamente el viejo Catón; el

24. Equivale a 4.500 denarios (Polibio usa el talento cistofórico: FerRer, 2005: 133), una cifra extraordinariamente elevada si la comparamos con los 400 denarios que podía costar un esclavo minero (FERRER, 2005: 140)

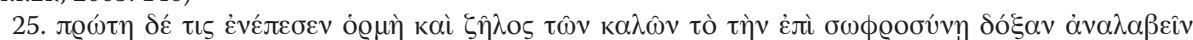

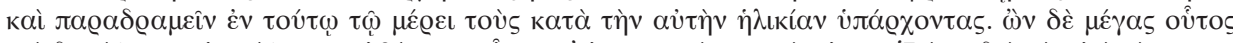

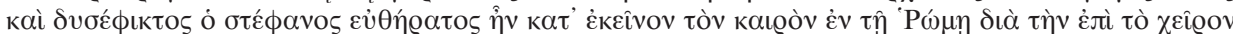

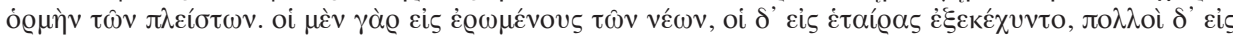

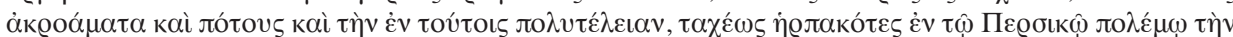

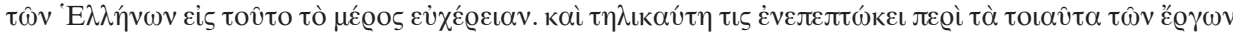

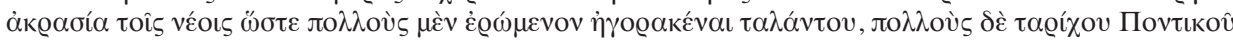

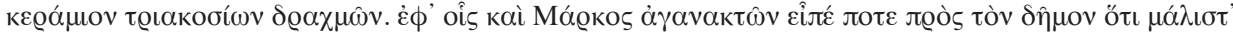

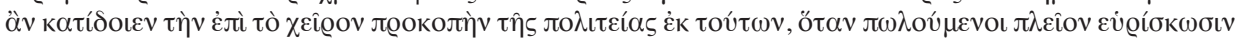

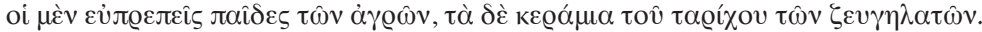


moralista y muy astuto Catón, que tanto gustaba de los gestos propagandísticos sobre los que sustentaba su fe en el modo tradicional republicano. ${ }^{26}$

Catón fue un ejemplo permanente para Cicerón: en el libro segundo de su tratado Sobre la República -donde recoge una descripción de todo el proceso histórico político de Roma-, se reafirma la conclusión catoniana de que la constitución romana representa la más perfecta de las formas de gobierno. Estas son sus convicciones, puestas en boca de Escipión:

Solía decir [Catón] que la constitución de nuestra ciudad aventajaba a las de otras ciudades, porque en ellas habían sido hombres aislados y cada uno de ellos había constituido la República con sus propias leyes e instituciones, como Minos la de Creta, Licurgo la de Lacedemonia, y la de Atenas había cambiado muchas veces por obra de Teseo, de Dracón, de Solón, de Clístenes y de otros muchos, finalmente la había sustentado un varón sabio, Demetrio Falereo, cuando ya se encontraba extenuada y moribunda. Nuestra constitución, en cambio, no era fruto del ingenio de uno solo, sino de muchos; ni se consolidó en una generación, sino que fue mudando a lo largo de los siglos y de las generaciones. Decía que no había existido ningún ingenio tan grande a quien no se le escapara alguna cosa, y que ni siquiera todos los ingenios del mundo reunidos en una sola persona podrían tomar tanta providencia en una sola edad, de considerar tantas cosas sin la experiencia y la tradición (Cic., de re publica, $2,1-2) .{ }^{27}$

Catón ensalza en esta cita la obra colectiva romana, tan distinta de los efímeros regímenes políticos que obedecieron exclusivamente al dictado de una sola persona; una sinergia de voluntades fruto de la experiencia y la tradición, cuyo objetivo se gana día a día y se atesora como un bien muy preciado. Con ese orgullo atávico como seña de identidad, resulta muy difícil aceptar innovaciones sociales que modifiquen radicalmente tal sedimento de sentido común y esfuerzo compartido. Y en ese rechazo hacia las costumbres importadas Catón fue inflexible. Para él los griegos eran inútiles e intratables, capaces de corromper y arruinar a Roma, y su defensa de la oligarquía romana más conservadora y la advertencia del «peligro griego» será recordada por

26. Con ocasión de la campaña contra los hispanos en 195 a. C., trató de convencer a propios y extraños con su ejemplo de austeridad, retirando del botín conquistado solo «lo necesario para comer y beber», añadiendo que deseaba «competir en virtud con los hombres virtuosos, más que en riqueza con los ricos y en avaricia con los avaros» (Plutarco, Cat. mai., 8); el mismo Catón que poco antes había expulsado a los redemptores, que abastecían al ejército en Hispania, justificando que «la guerra se alimenta a sí misma» (Livio, 34, 9, 12).

27. Is dicere solebat ob hanc causam praestare nostrae civitatis statum ceteris civitatibus, quod in illis singuli fuissent fere quorum suam quisque rem publicam constituisset legibus atque institutis suis, ut Cretum Minos, Lacedaemoniorum Lycurgus, Atheniensium, quae persaepe commutata esset, tum Theseus tum Draco tum Solo tum Clisthenes tum multi alii, postremo exsanguem iam et iacentem doctus vir Phalereus sustentasset Demetrius; nostra autem res publica non unius esset ingenio sed multorum, nec una hominis vita sed aliquot constituta saeculis et aetatibus. nam neque ullum ingenium tantum extitisse dicebat, ut quem res nulla fugeret quisquam aliquando fuisset, neque cuncta ingenia conlata in unum tantum posse uno tempore providere, ut omnia complecterentur sine rerum usu ac vetustate. 
escritores más tardíos. Plinio transcribe algunos fragmentos de los consejos de aquel a su hijo mientras le reprende con severidad: «te he prohibido tratar con médicos» (NatHist., 29, 14); ${ }^{28}$ o Plutarco: «para indisponer a su hijo contra las cosas de los griegos (...) dijo que los romanos arruinarían la república en cuanto se introdujeran las letras griegas por todas partes» (Cato. mai., 23).

Pero la realidad social fue distinta, los asuntos griegos fueron bien aceptados por un sector de ciudadanos romanos deseosos de adquirir una paideía de educación y cultura helenas, pues según Polibio había en Roma muchos griegos a los que Escipión Emiliano podía acudir para aprender. Naturalmente esta paideía no formaba parte de la esencia más conservadora de la cultura romana, y en tanto podía influir negativamente en ella era detestable.

En la suma de experiencias que constituía esa cultura tradicional se incluía la adaptación a nuevos modos políticos y sociales que conllevaba el curso de los acontecimientos. Naturalmente, siempre que esos modos surgiesen del interés de las clases dirigentes y no modificaran en absoluto su poder, como ocurrió durante el siglo iII a. C. en la paulatina acomodación al egoísmo económico que propició la gran expansión romana. El aprecio por el lucrum y los beneficios de la conquista, tan desigualmente repartidos, generaron enormes diferencias sociales y dieron origen a una nueva ética de la ciudadanía. Los viejos ideales basados en la pertenencia a un grupo social orgulloso de haber creado una República fuerte y respetable, favorecedora del cuerpo ciudadano que envolvía, fueron sustituidos por el individualismo y la utilización de las instituciones públicas en beneficio propio (FERRER, 2001).

Tal vez esta nueva actitud podría justificar los furibundos ataques de Catón al despilfarro público y al desaforado enriquecimiento privado; ${ }^{29}$ pero su postura puede conducir a engaño, en realidad la preocupación nace de su profundo sentido conservador del estado y del miedo a perder posiciones de privilegio interno. Frente a rivales iguales en condición social y política, solo cabe distinguirse por ideario, por pensamiento y por la expresión de un modo distinto al de aquellos de ver y entender la esencia de la patria.

Los ideales políticos de un Cicerón iluminado ${ }^{30}$ no se reconocen en las graves consecuencias que la expansión imperialista de Roma tuvo para su

28. En su tiempo la medicina era practicada mayoritariamente por individuos de origen griego (САMACHO, 1963: 43).

29. En sintonía con los sentimientos populares, más cercanos al ahorro y la moderación que al despilfarro y a la ostentación de riqueza (G. Tibiletti, 1953: 239-240).

30. Su convencimiento - real o ficticio- acerca del protagonismo que le correspondía en el entramado político romano le llevó a relacionar su salida al exilio con la llegada de los males y catástrofes arrostradas por Roma, mientras su regreso fue el equivalente del advenimiento de la recuperación material, la paz, la tranquilidad y la esperanza en el futuro (PINA, 2002: 63). 
propia comunidad. Su postura ideológica no se sostiene en el entramado de una república oligárquica que gestó en su seno el pecado de soberbia imperialista y la penitencia de una grave fractura social y política interna. ${ }^{31}$ Además, sus contradicciones y doble lenguaje, según se trate de mensaje público o correspondencia epistolar, restan credibilidad a su discurso. Sirva como ejemplo la comparación entre los dos siguientes fragmentos, donde la finalidad ideológica y doctrinal del primero contrasta con los intereses personales y el sentido práctico que se deduce del comentario privado $-\mathrm{y}$ probablemente más sincero- que transmite a su amigo Ático en el segundo:

En todo caso lo seguro es que como conviene que la ley sea la correctora de los vicios y la consejera de las virtudes, de ella hay que sacar la doctrina de la vida (Cic., de legibus, 1, 58). ${ }^{32}$

De momento pienso defender a mi colega de candidatura Catilina. Tenemos los jueces que queremos, con plena disposición de la acusación. Espero que, si es absuelto esté más dispuesto a cooperar conmigo en la campaña de la candidatura (Cic., ad Atticum, 1, 2). ${ }^{33}$

Apenas unos años después de la publicación de su ideario, Cicerón no tendrá ocasión de comprobar como «su» República y la de su admirado Catón, aquella que defendían con tanta vehemencia y admiraban como el resultado perfecto de una obra colectiva, acabará, por el contrario, convertida en la obra personal de un solo individuo.

Su alegato por los sentimientos que inspira la República, que, como vimos, es la patria común (de officiis, 1, 57), se verá afectado, a partir del siguiente siglo, por un nuevo concepto estoico expresado por Séneca (de vita beata, 20,5): «sabré que mi patria es el mundo y que los dioses lo presiden», ${ }^{34}$ en un estado dirigido por un príncipe y con él identificado, desprovisto de aquel carácter sentidamente colectivo que Catón tanto gustaba. En cuanto a su definición de la comunidad de ciudadanos (de re publica, 1, 39), que no hace sino expresar un sentimiento propio de la naturaleza humana, será transmitida posteriormente por Lactancio (div. inst., 6, 10, 18): «los hombres se reunieron por su horror natural a la soledad y la necesidad de vivir en comunidad y sociedad con sus semejantes», hasta hallarlo de nuevo formulado por la teoría contractualista, en los siglos XVII y XVIII, en los trabajos de Hobbes, Locke y finalmente Rousseau, expresando la idea de una sociedad unida por intereses

31. El ideario de este Cicerón egocéntrico y vanidoso tuvo menos repercusión en la política romana del que se desprende del conjunto de sus escritos (PINA, 2005: 407 ss.).

32. Sed profecto ita se res habet, ut quoniam vitiorum emendatricem legem esse oportet commendatricemque virtutum, ab eadem vivendi doctrina ducatur.

33. Hoc tempore Catilinam, competitorem nostrum, defendere cogitamus. Iudices habemus, quos volumus, summa accusatoris voluntate. Spero, si absolutus erit, coniunctiorem illum nobis fore in ratione petitionis.

34. Patriam meam esse mundum sciam et praesides deos. 
comunes, soberana y, por tanto, desprovista de absolutismos y tiranías. Los sentimientos que inspira la patria hallarán un excelente acomodo en las ideas nacionalistas del siglo siguiente, a pesar de la irrupción del romanticismo y la interferencia entre nacionalidad y ciudadanía, e incluso servirán para rechazar las posiciones conformistas con una sociedad injusta y desequilibrada: «los obreros no tienen patria», afirmarán Marx y Engels en el Manifiesto Comunista.

Pero el sentimental concepto ciceroniano de amor a la patria no desaparecerá. ${ }^{35}$ A finales del siglo xIX, Cánovas del Castillo, el personaje político más influyente del conservadurismo español, insistirá en ello: «Viene a ser así la patria, conciencia que cada nación posee de sí misma; y aun por eso cabe decir que la patria no ha existido ni existe en las aglomeraciones inconscientes de hombres, a quienes tan solo el instinto, o necesidades materiales y recíprocas, mantienen juntos, por más que formen ciudades y hasta grandes naciones. La patria es, donde en su plenitud se posee, aquel ente social que más íntimamente amamos, el que nos entusiasma más, el que mueve y electriza nuestra voluntad más fácilmente, y no pienso yo que esta voz nobilísima haya perdido tanto valor y hechizo como se supone, desde la antigüedad hasta ahora, ni en los corazones ni en los oídos». ${ }^{36}$

\section{BibLIOGRAFÍA}

Camacho, F. (1963): Las profesiones liberales en Roma, Granada.

De Blas Guerrero, A. (1984): Nacionalismo e ideologías políticas contemporáneas, Madrid.

Duplá Ansuategui, A. (2006): «Ciudadanía romana, nacionalidad e historiografía tardo-republicana: Roma e Italia», en F. MARCo Simón, F. Pina Polo, J. Remesal (eds.), Repúblicas y ciudadanos: modelos de participación cívica en el mundo antiguo, Barcelona, 207-220.

Ferrer Maestro, J. J. (2001): «Patriotismo y negocios. Una visión de la clase dirigente romana en el periodo de las guerras púnicas», en P. BARCELÓ, V. Rosenberger (her.), Beiträge zur Antiken Kulturgeschichte, Munich, 81-88.

Ferrer Maestro, J. J. (2005): La República participada. Intereses privados y negocios públicos en Roma, Castellón.

Leibholz, G. (1964): Conceptos fundamentales de la política y la teoría de la Constitución, Madrid.

Marco Simón, F., Pina Polo, F. (2000): «Concordia y libertas como polos de referencia religiosa en la lucha política de la república tardía», Gerión, 18, 261-292.

35. Duplá (2006: 208), coincide en hallar el origen del patriotismo moderno -que este autor sitúa a partir de Maquiavelo- en la concepción clásica ciceroniana.

36. A. CÁnOVAs del CAStillo, Discurso sobre la nación: Inauguración del curso del Ateneo de Madrid, noviembre de 1882, IV, 88. 
Pina Polo, F. (2002): «Cicerón, elegido de los dioses: la reprobación religiosa del adversario político como recurso teórico», en F. MARCo Simón, F. Pina Polo, J. Remesal (eds.), Religión y propaganda política en el mundo romano, Barcelona, 57-69.

Pina Polo, F. (2005): Marco Tulio Cicerón, Barcelona.

Rustow, D. A. (1974): «Nación», en Enciclopedia Internacional de las Ciencias Sociales, VII, Madrid, 301.

SCHeid, J. (1991): La Religión en Roma, Madrid.

Strasburger, H. (1956): Concordia ordinum. Eine Untersuchung zur Politik Ciceróns, Ámsterdam.

Tibiletti, G. (1953): Principe e magistrati repubblicani: ricerca di storia augustea e tiberiana, Roma. 